\title{
State of clinical research ethics in Pakistan
}

To the editor:

The News item ${ }^{1}$ published in your July issue discusses the potential problems with performing clinical research in developing countries. Although the article focuses on Africa, the issues are also relevant elsewhere, including in South Asia, particularly in light of the growing trend of outsourcing trials to that region ${ }^{2}$.

South Asian countries such as Pakistan are attractive sites for multinational clinical trials because of the availability of inexpensive research resources and naive volunteers and a high prevalence of chronic diseases $^{3}$. Half of Pakistan's population lives below the poverty line ${ }^{4}$, inducing people to participate in clinical trials in exchange for compensation or free medical treatment. Doctors in Pakistan also have high social status, and their patients often blindly trust them, subverting the process of informed consent.

Trial participants should ideally read and understand their consent forms before they decide to sign them, but illiteracy and a lack of awareness limit this exercise. Informed consent sometimes does not exist, and when it does it is crude and inadequate. About $40 \%$ of patients surveyed in Pakistan believe that proper documentation of consent is either unnecessary or optional ${ }^{5}$. The strong family support system in this country also means that senior family members sometimes make decisions for the trial participants. This is particularly true for female research volunteers, for whom permission must be sought from fathers or husbands 5 .

There is no federal regulatory authority in Pakistan that sets guidelines for clinical trials, although the government has taken some initial steps by setting up a National Committee on Good Clinical Practice and Good Prescribing Practice and a National Bioethics Committee ${ }^{3,6}$.

The formal concept of bioethics in Pakistan originated in 1984 with the establishment of the Aga Khan University (AKU) in Karachi.
Because AKU had active collaborations with Western universities such as McMaster University in Canada, there was an emphasis on ethics that, beginning in the mid-1990s, resulted in the incorporation of ethics into the curriculum of schools of nursing and medicine at AKU. In 2001, the Pakistan Medical and Dental Council ruled that ethics education must be imparted by all the medical and dental colleges in the country. This edict remains unfulfilled, however. AKU is one of only a few institutions in Pakistan to have an active ethical review committee 6 .

The Centre of Biomedical Ethics and Culture, established in Karachi in 2004, has taken the lead in training Pakistani medical professionals ${ }^{8}$ in ethics. A graduate program in clinical research at AKU has also begun training clinical residents and fellows, but not nurses or clinical research coordinators, as is commonplace in the West.

But these are small steps. Pakistan must do more to educate professionals at all levels, from technical staff to clinicians, in the concepts of ethical research.

\section{COMPETING INTERESTS STATEMENT}

The authors declare no competing financial interests.

\section{Muhammad N Ghayur, Ayesha Ghayur \& Luke J Janssen}

Department of Medicine, McMaster University, St. Joseph's Hospital, Hamilton, Ontario L8N 4A6, Canada.e-mail:nghayur@mcmaster.ca

1. Willyard, C. Nat. Med. 13, 763 (2007).

2. Benatar, S.R. Camb. Q. Healthc. Ethics 9, 562-565 (2000).

3. Sheikh, A.L. East. Mediterr. Health J. 12, S42-S49 (2006).

4. World development report 1998/99 (World Bank, Washington, DC, 1999).

5. Jafarey, A. East. Mediterr. Health J. 12, S50-S55 (2006).

6. Moazam, F. \& Jafarey, A.M. Camb. Q. Healthc. Ethics 14, 249-255 (2005).

7. Jafarey, A.M. Issues. Med. Ethics 10, 163-164 (2002).

8. Moazam, F. East. Mediterr. Health J. 12, S10-S12 (2006). 